VICTOR ROSENTHAL

\title{
MICROGENESIS, IMMEDIATE EXPERIENCE AND VISUAL PROCESSES IN READING
}

\author{
INTRODUCTION
}

The concept of microgenesis refers to the development on a brief present-time scale of a percept, a thought, an object of imagination, or an expression. It defines the occurrence of immediate experience as dynamic unfolding and differentiation in which the 'germ' of the final experience is already embodied in the early stages of its development. Immediate experience typically concerns the focal experience of an object that is thematized as a 'figure' in the global field of consciousness; this can involve a percept, thought, object of imagination, or expression (verbal and/or gestural). Yet, whatever its modality or content, focal experience is postulated to develop and stabilize through dynamic differentiation and unfolding. Such a microgenetic description of immediate experience substantiates a phenomenological and genetic theory of cognition where any process of perception, thought, expression or imagination is primarily a process of genetic differentiation and development, rather than one of detection (of a stimulus array or information), transformation, and integration (of multiple primitive components) as theories of cognitivist kind have contended.

The term microgenesis was first coined by Heinz Werner (1956) as a means of providing a genetic characterization of the structure and temporal dynamics of immediate experience, and, more generally, of any psychological process (Werner, 1957; Werner \& Kaplan, 1956; Werner \& Kaplan, 1963). But the genetic framework to which this term referred actually emerged in the mid-1920s in the context of Werner's work at the University of Hamburg and, to a certain extent, of the work of the Ganzheitspsychologie group in Leipzig led by Friedrich Sander. For Werner, microgenesis had not only a substantive (as a psychological theory) but also a methodological meaning. As a method, it either referred to genetic realization (Aktualgenese) which sought to provide the means of externalizing the course of brief perceptual, or other cognitive processes by artificially eliciting 'primitive' (i.e. developmentally early) responses that are normally occulted by the final experience (see in this respect Sander, 1930; Werner, 1956). Or it referred to experimental psychogenesis which aimed to construct small-scale, living models of large-scale developmental processes in such a way as to 'miniaturize' (i.e. accelerate and/or telescope) the course of a given process and bring it under experimental control. Experimental psychogenesis, devised by Werner in the 1920s, played afterwards an important role in the work of Vygotsky and Luria who further extended its field of application and gave it a historical dimension (Catán, 1986; Vygotsky, 1978; Werner, 1957, first German edition published in 1926; Werner \& Kaplan, 1956). As a theoretical framework, microgenesis constituted a rectification of Gestalt theory especially in regard to its overly structural and agenetic character ${ }^{1}$. Yet, together 
with the latter, microgenesis gave psychology its first cognitive paradigm. In its modern version, microgenesis offers a genetic, phenomenological alternative to the information-processing metaphor, an alternative that reunites mind and nature and restores to cognition its cultural and hermeneutic dimensions.

My purpose in this essay is to provide an overview of the main constructs of microgenetic theory, to outline its potential avenues of future development in the field of cognitive science, and to illustrate an application of the theory to research, using visual processes in reading as an example. In my overview, I shall not dwell on the history of microgenesis (the reader may find the relevant sources in Catán, 1986; Conrad, 1954; Sander, 1930; Werner, 1956; Werner, 1957; Werner \& Kaplan, 1956) but rather describe its main constructs from a contemporary perspective.

\section{MICROGENETIC DEVELOPMENT}

Microgenetic development concerns the psychogenetic dynamics of a process that can take from a few seconds (as in the case of perception and speech) up to several hours or even weeks (as in the case of reading, problem solving or skill acquisition). It is a living process that dynamically creates a structured coupling between a living being and its environment and sustains a knowledge relationship between that being and its world of life (Umwelt). This knowledge relationship is protensively embodied in a readiness for further action, and thereby has practical meaning and value. Microgenetic development is thus an essential form of cognitive process: it is a dynamic process that brings about readiness for action ${ }^{2}$. Microgenesis takes place in relation to a thematic field which, however unstable and poorly differentiated it might be, is always given from the outset. To this field, it brings stabilized, differentiated structure and thematic focalization, thereby conferring value and meaning to it. Figure/ground organizations are an illustration of a typical microgenetic development. Yet, one should bear in mind that however irresistible an organization might appear, it is never predetermined but admits of alternative solutions, that a 'figure' embodies a focal theme, and that a 'ground' is never phenomenologically or semantically empty. Thematic field denotes here a definite field of consciousness, and has both phenomenological and semantic meaning (see Gurwitsch, 1957). Focal thematic embodiment of microgenetic development thus differs from unfocussed, heterogeneous, and heterochronic ontogenesis, which spans a considerable portion of life and requires organic maturation and growth (see Werner, 1957, for a discussion of differences between microgenetic development and ontogenesis; Werner \& Kaplan, 1956).

\section{MEANING AND FORM}

It should be noted that form, meaning and value are not considered separate or independent entities. According to microgenetic theory, whatever acquires the phenomenological status of individuated form acquires, ipso facto, value and meaning. This may not necessarily be a focally attended meaning, as the definite 
experience of meaning depends on whether a form is given a focal thematic status. Yet, regardless of the status of the meaning experience, microgenetic theory postulates that form has of necessity semantic and axiological extensions. Incidentally, this point highlights the radical opposition between microgenesis and the standard cognitivist stance, where form, meaning and value are deemed independent and mobilize processes that are intrinsically alien to one another. If meaning and value are acknowledged to affect perception, as the seminal experiment of Bruner and Goodman (1947) revealed by showing that the size of a coin is seen as bigger when it is highly valued, it is assumed that this influence obtains via the interaction of processes. Yet no precise explanation has been supplied as to how structurally different processes, which deal with incommensurable factors, can ever interact with one another ${ }^{3}$. Werner and Wapner (1952) observed many years ago, that theories which separate sensory, semantic, motivational and emotional processes, and view perception as a construction of abstract forms out of meaningless features (only to discover later their identity and meaning), face in this respect insurmountable paradoxes. If semantics postdates morphology, then it cannot affect form reconstruction, and if semantics is concomitant with form reconstruction, how can it influence morphological processing prior to 'knowing' what the latter is about? Finally, since morphological and semantic processes are viewed as incommensurable, how can they be brought to cooperate together without recourse to yet another, higher-order process? Invoking such a process would either amount to conjuring up a sentient device of the homunculus variety or would stand in contradiction to the very postulate of the distinctness and independence of meaning and form.

\section{CATEGORIZATION}

According to the present account, no such interaction is to be sought because meaning and form are not separate or independent entities; on the contrary, perception is directly meaning and value-laden, with actual meaning developing along the global-to-local (indefinite/general-to-definite/specific) dynamics of microgenesis. The gradual differentiation of a meaning, percept or concept involves a global-to-local course of development, where meaning and value go hand-in-hand with perceptual or cognitive organization, developing from vague and general to definite and specific. Note, though, that no direct holistic principle can be viable if it does not rely on a process of categorization. Immediate categorization represents another essential feature of microgenetic development: it provides the dynamic link between holistic differentiation, meaning and readiness for action. Consider, indeed, that even the most basic categorization has meaning - meaning is thus not the end product of perception but rather part and parcel of the perceptual process ${ }^{4}$. The psychological literature gives ample evidence of the fact that subjects carry out basic categorization instantaneously (e.g., discrimination of relevant from irrelevant stimuli), without first making a more complete identification of the stimuli, and that preliminary categorization improves the rate of definite identification (Brand, 1971; Ingling, 1972). It should also be emphasized that categorization necessarily 
delineates a horizon of action, a horizon that comprises a range of relevant acts that the subject may potentially be compelled to enact.

Perception can then be said to act under the assumption of the consistency and meaningfulness of the world in which we live: the perceptual system 'assumes' that whatever it encounters has structure and meaning. It therefore anticipates and actively seeks meaningful structures (objects) and immediately categorizes them on a global dynamic basis ${ }^{5}$. Microgenetic theory contains here a hermeneutic principle: in order to be meaningful, perception must consist in dynamic categorization evolving from general to specific, from vague and global to precise and local (see Rastier, 1997). Incidentally, this explains why the 'germ' of the final percept is already embodied in early stages of the perceptual process. Immediate categorization allows for the categorical continuity of forms throughout the entire perceptual process giving cohesiveness and stability to the perceived world (see Cadiot \& Visetti, 2001; Gurwitsch, 1966, chap. 1). This primary categorization may be insufficient for the precise and overt perceptual identification of objects - as required by standard psychological experiments - and may then need to be completed by a process of local discrimination. This complementary discrimination, necessary for the focal thematization of a 'figure', is greatly constrained by the former process; it operates within a restricted categorical domain, and can thus bear selectively on the properties of the percept that are distinctive. From a phenomenological viewpoint, discrimination is what brings about the overt identification of a percept.

\section{BREAKING UP THE HOLISTIC FABRIC OF REALITY}

The segmentation of the perceptual field into individual objects is thus the result of perceptual differentiation, and not the objective state of affairs that perception would merely seek to detect and acknowledge. In this sense, microgenesis is the process that breaks up the holistic fabric of reality into variably differentiated yet meaningful objects, beings and relations. From Aristotle to Poincaré and Thom, scores of philosophers and mathematicians have speculated about the ontological precedence of continuum over discrete structures, and suggested that individuated forms are created by breaking up the continuous fabric of reality, and not the other way around. From the microgenetic viewpoint, we may invoke genetic ${ }^{6}$ precedence of continuum over discrete structures, where categorization and dynamic thematization act as organizing principles in breaking up the continuous fabric of reality into individuated forms.

The idea of the genetic precedence of holistic fabric over individuated forms in the course of perceptual differentiation runs counter to standard cognitivist theories where form perception is basically viewed as a reconstruction from components (or elementary features), followed by the projection of the reconstructed object onto the internal screen of the mind (i.e. representation). It bears noting that the idea of a projection onto a mental screen is phenomenologically vacuous (i.e. provides no explanation of perceptual experience) and smacks of a homunculus (it takes a homunculus to contemplate the screen). Yet, since phenomenological issues seldom 
preoccupy the proponents of cognitivism, and they bluntly dismiss any alternative perspective - confident as they are that their theoretical stance will ultimately be corroborated by neurophysiological and psychological evidence - we may provisionally embrace their concerns and examine the issue of elementary features. Because any real form can be decomposed into a countless number of features, and what makes a useful feature in one case may have little utility in another, one may wonder how the perceptual system is able to pick in advance the useful features of an as yet unreconstructed form. A way out of this problem might be to suggest the existence of a finite set of generic features that could be made use of in the (re)construction of any possible form. But then there would be tremendous differences with respect to the ease with which various forms are reconstructed, and the task may even turn out to be impracticable in the absence of an organizing principle, which, again, would have to be known in advance. Clearly, the proposition that perception is based on reconstruction from elementary components raises more problems than it may be expected to solve.

\section{PRESENT-TIME EXPERIENCE}

Optics, acoustics, chemistry, topology, as well as technological metaphors of photography, motion pictures, television or recording devices have, during the past century, greatly inspired scientific theorizing on perception. In their physicalistic fervor, generations of psychologists and neuroscientists alike somehow lost sight of the very phenomenological character of reality, let alone the necessity of explaining why present-time experience has continuity and depth. Why is it that what occurs in present-time is not infinitely brief, that experience does not consist of a kaleidoscopic succession of disconnected instants but has consistency and duration? Bergson, Husserl, and Merleau-Ponty, to mention the most outstanding authors, have penetratingly described and analyzed the issue of a non-evanescent present, of which my own description would be a pale rendition. Let me underscore, nevertheless, that perception critically involves an enduring and consistent presence in experience. This presence signifies that there is a continuous structure to experience, or more properly, a continuous forward-oriented dynamics, so that the present-time is neither infinitely brief nor evanescent, but has depth (or thickness) and consistency stretching dynamically from its immediate predecessor to its anticipated successor. To use Husserl's terminology, the now has retentions and protentions. Perception theorists who keep on brushing aside this continuous forward-oriented dynamics of present-time experience can be likened to conscientious parents who throw their baby out with the bathwater. Even if one were to regard the perceptual field as a kind of external memory - to quote a recent theory (O'Regan, 1992) - where any part of the field is kept available for further inspection - this very availability critically depends on the continuous dynamics of a forward-oriented stretch of present-time. Were this not so, the issue of availability for further inspection would be pointless as, at each and every instant, the perceptual process would have to start anew. Whatever is present in experience is so by virtue of a process that dynamically extends in time. This presence in experience 
is by no means illusory, if by illusory one implies something unreal, because the only reality available to us is the one we experience.

\section{DUAL DYNAMICS OF TIME: UNFOLDING AND DEPLOYMENT}

It is my suggestion that microgenetic theory provides an adequate framework for the explanation of this dynamic process. To show how, I shall first introduce the concept of autochrony which refers to the internal, unidirectional (i.e. forwardoriented), self-generated time characteristic of the living process (Rosenthal, 1993). This self-generated, internal time, which determines the flow of the living process and is proper to each living species, has a phenomenological and biological meaning. It confers on temporal dynamics its intrinsic direction as well as the periodicity specific to each species ${ }^{7}$. It is at the very heart of the autonomy of action and provides the latter with its driving impulse. Note, indeed, that in order to be autonomous, rather than merely reactive, an action has to be self-generated. Yet, if we are to account for the continuous forward-oriented dynamics of present-time experience, what is further required is the idea of a dual dynamics of microgenetic development, one of unfolding and one of deployment ${ }^{8}$. Experience has consistency and duration because it has a developmental history, a history that diachronically deploys and unfolds. Unfolding refers to the developmental succession of intermediate phases of ongoing experience, whereas deployment designates the fact that a figure has temporal extension, the time it takes to deploy in experience. This dual dynamics of microgenetic development, whereby experience gradually unfolds through differentiation and the deployment of intermediate figures, and where successive deployments tend to occult their predecessors but not the very sense of developmental history, confers on present-time experience its temporal depth and consistency. There is thus depth and consistency in the present-time because we sense the developmental history of ongoing experience without being able, at least usually ${ }^{9}$, to evoke its intermediate deployments, as they are occulted by the current occurrence of the present.

The cohesiveness of gradually unfolding present-time experience depends also on the anticipatory and categorial character of microgenetic development. Categorization allows for the continuity of form identity throughout perceptual development, giving it cohesiveness and stability. Anticipation, which should not be mistaken for the effective expectation of definite objects or states of affairs, designates a protensive readiness for action: we actively anticipate and seek meaningful structures and immediately categorize them in view of prospective action.

\section{GRADUAL CHARACTER OF IMMEDIATE EXPERIENCE}

The hidden, gradual character of immediate experience attracted considerable attention on the part of the founders of microgenetic theory. The method of genetic realization (Aktualgenese) was actually developed by Sander in order to externalize 
the course of microgenetic development by artificially eliciting 'primitive' (i.e. developmentally early) responses which are normally occulted by the final experience (Sander, 1930; Werner, 1956). In the field of visual perception, this was accomplished by repeatedly presenting very brief, poorly lit or miniature stimuli, and gradually increasing exposure time, improving lighting or letting the stimulus grow to 'normal' size. The subjects or, more appropriately, the observers were invited to describe what they perceived and felt as the experiment unfolded. Sander provided minute descriptions of these 'primitive' responses, observing that "the emergent perceptual constructs are by no means mere imperfect or vague versions of the final figure (...) but characteristic metamorphoses with qualitative individuality, 'preformulations' (Vorgestalten)" (ibid, p. 193). He noted that in the course of an unfolding perception, the development does not amount to a steady, progressive improvement whereby each successive deployment is a more elaborate version of its predecessor that comes closer to the final percept. Rather, the development observed in Aktualgenese exhibits the characteristic structural dynamics at work in perception. "The formation of the successive stages, which usually emanate one from the other by sudden jerks, has a certain shading of nonfinality; the intermediaries lack the relative stability and composure of the final forms; they are restless, agitated, and full of tensions, as though in a plastic state of becoming." Moreover, "this structural dynamics, which (...)[is] one of the determining factors in the process of perception itself, enters our immediate experience in the form of certain dynamic qualities of the total 'state of mind', in emotive qualitative tonalities" (p. 194).

The structural dynamics at work in an unfolding perception generates intense emotional involvement on the part of the experiencer. The perceptual development, artificially externalized by the method of Aktualgenese, is not something the observer follows with cool objectivity and detachment, but "all metamorphoses are engulfed in $\mathrm{a}[\mathrm{n}]$... emotional process of pronouncedly impulsive and tensor nature, and take place through an intense participation of the whole human organism" ( $p$. 194). There is an 'inner urge' for 'formation of the ill formed' and for meaningfulness. The intermediate deployments are thus experienced with a 'peculiar feeling-tone' correlated with the instability and non-finality of a given occurrence and are animated by the dynamics of what Sander's gestaltist counterparts called Prägnanz (the 'urge' for symmetry, regularity, homogeneity, simplicity, stability...). The emotional involvement observed in genetic realization, which could be viewed as excessive in regard to an unremarkable object of actual perception, can nevertheless be experienced under 'normal' conditions. A picture hanging crooked on the wall can become unbearable and can literally shriek to be set straight.

Werner gave a markedly similar description of these structural dynamics at work in microgenetic development and of the intermediate deployments that are occulted by the final experience, placing an emphasis on total bodily feeling, emotionalkinesthetic dynamics and action-like inner gestures. But he was more concerned with the semantic aspects of microgenesis and specified the characteristics of meaning stabilization and differentiation (Werner, 1930; Werner, 1956; Werner \& Kaplan, 1956; Werner \& Kaplan, 1963). In particular, he noted an early emergence of the general sphere of meaning, and described the developmental dynamics of 
meaning structure as characterized by sphere-like deployments, where gradual differentiation is not necessarily accomplished by contracting the semantic sphere but also involves shifts of the 'center of gravity'. Thus a target 'cigar' may at one point elicit the "primitive" response 'smoke', at another, 'cancer'. Some of the most interesting observations he made stemmed from neuropsychology where pathological behavior due to brain damage was described as an arrest of the microgenetic process at an earlier stage of development so that patient's responses took the form of unfinished 'products' which would normally undergo further development (see Conrad, 1954; Semenza, Bisiacchi, \& Rosenthal, 1988; Werner, 1956).

\section{THEMATIC ORGANIZATION OF CONSCIOUS EXPERIENCE}

The foregoing descriptions of microgenetic experiments shed light on the nonunitary and gradual character of conscious experience. For one thing, the thematic organization of conscious experience does not amount to mere contrastive juxtaposition where the theme (focal figure) is granted focal awareness and the ground is phenomenologically empty. Background objects are not speechless; they hang together with the theme as a sort of supportive frame, yet each brings in its intentional horizon and thereby constitutes a potential landmark for alternative thematic organizations. Moreover, thematic organization is not inherent to the field and is largely dependent on the subject's engagement in action; accordingly, access to phenomenal sensations depends on this engagement in action. Thus, for instance, physically the same perceptual context can give rise to different reports depending on the type of action in which the subject is involved (see e.g. Marcel, 1993). Finally, although the history of a microgenetic development is usually obscured by the final deployment, both the Aktualgenese experiments and the elusive fading impressions of intermediate deployments we sometimes have (and which are not necessarily imperfect versions of the final figure) suggest that conscious experience develops gradually and that the organization of the thematic field undergoes successive adjustments. These dynamic characteristics of conscious experience bear witness to the importance of the concept of structural instability for the theory of immediate experience.

\section{PHYSIOGNOMIC CHARACTER OF PERCEPTION}

The overall dynamic structure of microgenetic development may also account for the physiognomic character of perceptual experience. Physiognomic means here that we perceive objects as "directly expressing an inner form of life" (Werner, 1957, p. 69), that is, in the same manner in which we experience physiognomies, facial expressions, gestures, or, more generally, acts of living beings. Following this line, perceived forms are not static morphological configurations but dynamic deployments, where the overall 'dynamic tone' is part and parcel of the experienced percept $^{10}$. Accordingly, all perceived objects, whatever their nature, partake of 
physiognomic qualities. The physiognomic character of perception has been extensively discussed by Werner and also by Köhler $(1938 ; 1947)$ and Arnheim (1954; 1969), but the idea of physiognomic perception also prompted a series of misunderstandings, most notably on the part of Gibson (1979) and Fodor (1964). It should be observed that two aspects of physiognomic perception must be taken into account. The first concerns the expressive character of percepts, and the second the conative dimension of perception whereby the readiness for action imbedded in perceptual experience 'urges' us to act upon, or use, perceived objects (see also the concept of gerundival perception in Lambie \& Marcel, 2002). Gibson's concept of affordance, an anglicized version of Kurt Lewin's Aufforderungscharakter (invitation character), is partly grounded on this latter idea, though it doesn't convey the sense of an urge to act but merely invokes an invitation. This urge to action is most readily observed in the behavior of children, in so-called 'primitive peoples', and under the influence of certain drugs (Werner, 1957). Brain pathology gives an amazing example of the conative character of perception in so-called utilization behavior where the patient cannot but use whatever object he or she happens to come across (Lhermitte, 1983; Shallice, Burgess, Schon, \& Baxter, 1989). As Lhermitte observed, for the patient, the perception of an object implies the order to grasp and use the object. As the above example suggests, this pathological behavior is by no means an aberrant creation of pathology, but an expression of the readiness for action imbedded in perceptual dynamics. In the social context of Western Societies, this readiness for action does not necessarily prompt effective object manipulation, at least in adult behavior, but in the context of certain brain lesions enactment may become irresistible.

The expressive character of perception is obviously no less imbedded in perceptual dynamics. As Köhler and Arnheim cogently argued, the expressivity of the perceived world is directly experienced by the perceivers and does not result from empathic projection or from perceived analogy with their own past expressions and feelings. For one thing, we cannot simultaneously be external observers and the experiencers of our own interiority and exteriority. How could we then acquire the dual knowledge that would serve as the basis for an analogy? Second, the analogy could only hold between comparable entities or configurations; yet when we perceive a sad tree, a cheerful landscape, or the lovely face of Dorothée, this can hardly be due to the knowledge of our own expressions of sadness and cheerfulness, or, for the present writer, of his own loveliness. Clearly, an indirect principle, whereby perceived morphologies or dynamic configurations (e.g. facial expressions, gestures) are subsequently interpreted by analogy or empathic projection, can hardly count as a satisfactory explanation of the expressivity of the perceived world. On the contrary, expressivity constitutes a forceful illustration of the dynamic principle at work in perceptual development whereby even the morphology of static forms is grounded in the configural dynamics of the deployment of the percept ${ }^{11}$.

The acknowledgement of the physiognomic character of perception shouldn't be naively interpreted to suggest that our everyday perception is overflowing with an expressive world where objects and landscapes are animated by inner life. As adult members of Western Societies we certainly do not find ourselves overwhelmed by the expressivity of the perceived world - we generally barely pay attention to it - 
and many people will even be reluctant to admit that their perceptual experience has an expressive flavor. The expressivity of the perceived world is clearly at odds with the matter-of-fact style of our social world. In a labor-oriented society - where activity is governed by non-immediate goals and where, as Benny Shanon noted ${ }^{12}$, voluntary ignorance of a good deal of what we are otherwise able to perceive but what falls outside the tacitly agreed upon terms of relationships, is one of the founding components of interpersonal relations - physiognomic impressions normally recede to the background and form, at best, an elusive feeling tone. The perception of inanimate objects is no less affected by the style of our social world, for we belong to social world even when alone. Yet, reports of physiognomic perception abound in child psychology, ethnopsychology and clinical psychology. Children, so-called 'primitive peoples' and, for instance, certain schizophrenics manifest in their behavior clearly identifiable reactions to the perceived expressive character of objects. Moreover, the ease and the naturalness with which we are receptive to expressivity in literature, painting or music would remain inexplicable were we not to assume that this receptiveness builds upon a disposition that was 'already there'. Clearly, these observations testify to expressivity in perception. The acknowledgement of the physiognomic character of perception brings us closer to a scientific explanation of the origin of esthetic and ethical attitudes. Although for many students of cognition this issue is secondary or falls beyond the scope of a scientific endeavor, I submit that the inability of cognitivist theories to account for the origin of esthetic and ethical attitudes, their failure to even perceive the fundamental status of esthetics and ethics in regard to human cognition, constitute some of their major shortcomings. It is certainly not irrelevant that Gaetano Kanizsa, whose work inspired this collection of essays and whose phenomenological orientation resolutely opposed cognitivist approaches to perception, was deeply concerned with perception's esthetic character as well as being an accomplished painter.

\section{GENETIC PHENOMENOLOGICAL SCIENCE OF COGNITION}

The basic constructs of microgenetic theory outlined so far may be viewed as landmarks for a genetic phenomenological science of cognition. A reader familiar with Gestalt theory will easily recognize in this overview the legacy of Wolfgang Köhler, in particular his idea of stabilization in dynamic system and his concepts of value and expressivity in perception. These ideas are, however, reformulated to take into account temporal dynamics so as to be able to define cognitive process in terms of a dynamic development characterized by gradual differentiation and deployments, variable stabilization as well as unfolding and thematic focalization. This micro-development has an anticipatory and categorial character, to which, strangely enough, the gestaltists paid little attention.

It should be stressed that the phenomenological character of microgenetic theory does not prevent it from being amenable to evaluation by the methods of natural science. Much as the original theory of Werner has built on ample experimental evidence, various specific postulates of the present theory may be subjected to 
experimental evaluation in psychology and neuroscience where, incidentally, a variety of tools to probe brain dynamics have recently been devised. Note that experimental evaluation does not require that phenomenology be naturalized. The very idea of an experimental phenomenology is precisely to bring a naïve openness on the part of the subject, uncontaminated by formal knowledge, to the experimental situation, with its precise physical measures and control of experimental variables. Similarly, a comparable naïve openness is required on the part of the scientist whose genuine questioning free of conceptual prejudice is the only way to 'get in touch' with the original reality he seeks to describe, and, as such, is the necessary counterpart of his otherwise naturalistic stance (see Bozzi, 1989; Rosenthal \& Visetti, 1999; Vicario, 1993). In the next section, I shall briefly review neurophysiological, neuroanatomical, and eye-movement data and suggest that the bulk of available evidence is basically consistent with the notion of a global-to-local developmental dynamics in visual perception and the idea of the gradual differentiation of the percept. However, before I turn to this data, I should like to point out that some of the most promising developments for microgenetic theory in the field of cognitive science might be sought in the use of the modern mathematical and physical concepts of instability, and in the application of the theory of complex systems in modeling the dynamics of microgenetic differentiation (see also Visetti, this volume).

\section{EARLY STRUCTURE IN VISION}

There is a predilection among many vision scientists for the traditional atomistic explanation of visual perception according to which the putative percept is reconstructed at the level of the higher cortical structures from unstructured mosaic of elementary sensations that are produced on the retina and dispatched via retinofugal pathways to these cortical structures ${ }^{13}$. I shall argue, to the contrary, that the anatomical and physiological studies of the retinofugal pathways in primates support the proposition that considerable structure emerges already at the lowest levels of visual processes, and that these studies lend credence to the idea of holistic precedence, as well as, indirectly, to the overall schema of global-to-local structure of visual processes involving early categorization.

Retinal projections to the cerebral cortex are dominated by two major pathways, the magnocellular $(\mathrm{M})$ and parvocellular $(\mathrm{P})$ systems, which are relayed by the magnocellular and parvocellular subdivisions of the lateral geniculate nucleus (see Merigan \& Maunsell, 1993; Shapley \& Perry, 1986). The M ganglion cells have large soma, with extensive dendritic trees and large axons, whereas the $\mathrm{P}$ ganglion cells have smaller soma, small dendritic arbors and medium-size axons (see Leventhal, Rodieck, \& Dreher, 1981). It is important to note that the conduction velocity of $\mathrm{M}$ cells is greater than that of $\mathrm{P}$ cells due to the larger axonal diameter of $\mathrm{M}$ cells. Moreover, the $\mathrm{M}$ cells have large receptive fields, rapid temporal dynamics, and are more sensitive to low spatial frequencies. This system is sensitive to the coarse spatial distribution essential to the differentiation of basic form and for figure-ground segregation. The $\mathrm{P}$ system, which has smaller receptive fields and is 
more sensitive to higher spatial frequencies, samples the retinal image with higher resolution that is relevant to local spatial detail and color. There seems to be a division of labor between the two systems such that the M system quickly processes coarse form and the $\mathrm{P}$ system subsequently specializes in fine detail and color. The two systems thus sense different but overlapping portions of visible spatial and temporal frequencies (Livingstone \& Hubel, 1988). In a word, retinal 'sensations' are processed twice in a nonredundant fashion and each time using 'data' in a different format. Arguably, the M system provides a quick primal glimpse of the visual field, supplying sufficient structural information about gross spatial discontinuities and their position in the field to guide the processing of the $\mathrm{P}$ system. This enables the oculomotor system ${ }^{14}$ to adjust gaze position and generates dynamic displacement thereby creating spatio-temporal discontinuities to which the M system is also sensitive (see Lehmkuhle, 1993; Merigan \& Maunsell, 1993). Two important points emerge from this description. (1) Since the magnocellular system has temporal precedence, the earliest processes in vision are necessarily global and coarse-grained. (2) As the M ganglion cells have large receptive fields and are sensitive to coarse spatial distribution, displacement and temporal dynamics, there are reasons to believe that the $\mathrm{M}$ system segments the visual field on the basis of gross spatial and temporal discontinuities and of their joint displacement ${ }^{15}$. These observations strongly favor the proposition that the 'stimulus' brought by the magnocellular projection in V1 (striate cortex) already has considerable structure.

The notions of a global-to-local developmental dynamics in visual perception and of an early categorization of visual forms will, however, best be evaluated by combining the foregoing anatomical and physiological considerations with evidence from eye movement studies. It should be noted that the magnocellular system is mostly involved in extrafoveal (both parafoveal and peripheral) vision whose definition is insufficient for local detail, that it presumably exerts control on eye movements, and that foveal fixations (necessary for the exploration of local detail) are highly selective and cover only a small part of the visual field, mainly the figure (see O'Regan \& Noë, 2002; Underwood, 1998; Yarbus, 1967). This selectivity is obviously inconsistent with the 'mosaic theory', at least as far as the whole visual field is concerned, for how can the visual system reconstruct the whole field when over $80 \%$ of its 'elementary components' are unavailable. But selectivity is also interesting for other reasons. In order to act selectively a system has to have prior 'knowledge' on which to base the selection. In this case, the system has to spot the figure first and, then, adjust the gaze so as to fixate parts of this figure. Now, several characteristics of what makes up a figure need to be recalled: (a) it is a form, (b) it is necessarily meaningful, and (c) it has thematic prominence with respect to the rest of the field. But how can this come about were we first to construct abstract forms out of meaningless features, only to discover later their identity and meaning? Obviously, such a form could not first be (re)constructed out of the mosaic of its local meaningless components, and then targeted for central fixation, because local components can only be explored when fixated in central vision. Incidentally, this observation lends further support to the above proposal that basic form emerges in early coarse vision. But since the form in question is also a figure standing in the field, it comes accompanied by its semantic and thematic extensions. One can hardly explain how a figure can be spotted in early coarse vision if visual perception 
did not have a directly categorial and anticipatory character. Moreover, since early vision can at best provide a raw sketch of the figure, which may then be further explored in central vision, there are reasons to assume that the postulated schema of global-to-local coarse-grained-to-fine-grained differentiation in visual perception rests on firm grounds.

\section{SUBJECTIVE FIGURES}

Various phenomena of perceptual completion, whether figures, surfaces or regions, provide an interesting illustration of microgenetic dynamics at work in perception. Consider the famous example of the Kanizsa square where a collinear arrangement of edges of four white 'pacmen' (inducers) on a black background gives rise to the perception of a black square whose area appears slightly darker than the background. In addition, the surface of the square appears to the observer to be in front of four disks that it partly occludes. Since the square is perceived in spite of the absence of corresponding luminance changes (i.e. forming complete boundaries), and thus does not reflect any real distal object, it can only be created by the visual system which purportedly completes, closes, and fills in the surfaces between 'fragments', so as to make the resulting 'subjective' region emerge as figure standing in the ground. Yet, as Kanizsa $(1976 ; 1979)$ aptly showed, this and other examples of so-called subjective contours demonstrate the basic validity of Gestalt principles of field organization, in particular of its figure/ground structure and of Prägnanz, whereby incomplete fragments are, upon completion, transformed into simpler, stable and regular figures. Although this phenomenon is often described in terms of contour completion, it clearly demonstrates a figural effect, whereby the visual system imposes a figural organization of the field (and hence figure completion), and where the contour results from perceiving a surface, not the other way around, again as Kanizsa suggested. Moreover, these subjective figures illustrate the categorial and anticipatory character of microgenetic development, such that the perceptual system anticipates and actively seeks meaningful structures and immediately categorizes them on a global dynamic basis ${ }^{16}$. The crucial role of meaningfulness is demonstrated by the fact that no subjective figures arise in perception when the spatial arrangement of inducers does not approximate a 'sensible form' or when the inducers are themselves meaningful (viz. complete) forms ${ }^{17}$.

What makes these subjective figures even more valuable for the present discussion is that they may be viewed as an instantiation of early structure and of holistic precedence in visual development. In recent years, there has been considerable debate in vision science concerning the neural mechanism underlying perceptual filling-in and several researchers have claimed to have identified subpopulations of cortical cells specialized in various aspects of perceptual completion (see e.g. Lesher, 1995; and Pessoa, Thompson, \& Noë, 1998, for a review and critical discussion). One problem with these postulates of low-level filling-in neural mechanisms is the frequent confusion between what pertains to receptive field dynamics related to blind spot or scotomata and what pertains to the 
perception of genuine subjective figures. Another problem is that finding neurons whose behavior correlates with the perception of subjective figures does not imply that these neurons are actually responsible or even used for perceptual completion. The next problem is that no subpopulation of specialized cells can account for the fact that subjective figures are always sensible meaningful forms. Finally, many studies have tended to overstress the importance of contour (which as Kanizsa showed is secondary to surface perception) and thus assumed a critical role for collinear alignment of edge inducers when actually such alignments are not a necessary condition (as the Sambin/Kanizsa cross examples demonstrate, see Figure 1 below, and Kanizsa, 1976). It is important to note in this respect that there is presently a considerable body of neurophysiological and neuropsychological evidence supporting the idea that surface formation and completion, involving context-dependent figure/ground segregation, occurs very early in the course of vision and on global basis (Davis \& Driver, 1994; Lamme, 1995; Mattingley, Davis, \& Driver, 1997). This evidence confirms Kanizsa's results and further corroborates the microgenetic postulates of the dynamic, directly categorial (viz. meaning-laden) and anticipatory character of field organization. Although many scientists among the neuroscience intelligentsia continue to favor a modern version of the helmholtzian doctrine according to which the percept (here the subjective figure) is reconstructed at the level of 'sentient' higher cortical structures from an unstructured mosaic of elementary sensations processed by specialized local detectors, I submit that the above examples and discussion provide powerful arguments in support of the microgenetic theory of perceptual development outlined in this essay.

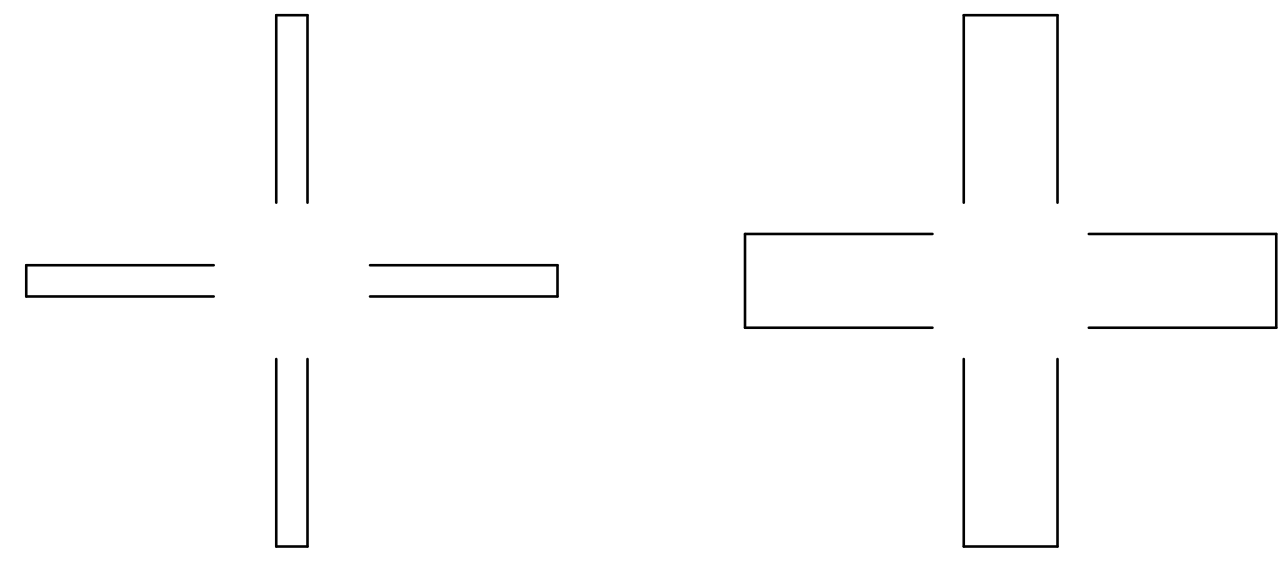

Figure 1. Sambin-Kanizsa cross examples. Note that the subjective surface in the center of the thin cross (left) has the form of a circle whereas the subjective surface in the center of the thick cross has the form of a square. 


\section{THE MICROGENESIS OF VISUAL PROCESSES IN READING}

I shall turn now to a specific illustration of certain principles of microgenetic theory in the field of reading. I have chosen reading because it is a peculiar skill. It takes both language and perception to become a reader, yet language and perception won't suffice; some people never become proficient readers, and a brain lesion can disrupt reading skills in subjects otherwise showing no defect in object perception and spoken language. The persistence of oral civilizations and of nonliterate societies further teaches us that not any form of social world is appropriate for the advent of literacy. Moreover, the passage from nonliterate to literate society deeply alters syntax, vocabulary and language use, as well as the mnemonic and cognitive practices of society members, and, ultimately, the society itself. At the same time, reading is interesting for our purpose as it handily lends itself to the evaluation of the postulates of immediate categorization and meaningfulness, selectivity, and the global-to-local structure of perceptual development.

Language and perception are unsettling accomplices of literacy. Their relationship involves a kind of co-determinism where it is difficult to regard written language as a simple externalization of information, lying 'out there' and waiting to be identified and reinternalized. Wertheimer once observed that for a proficient literate individual it is neither necessary to identify each individual letter nor to overtly recognize every word while reading a text. In 1913, he and Pötzl reported on an alexic patient who had "lost the ability to perceive words as gestalts". In spite of his preserved capacity to recognize individual letters, the patient was practically unable to read words; his preserved ability to identify component letters (elementary segments) along with the inability to recognize words (functional wholes) - which, incidentally, proved to be unresponsive to training - constituted in Wertheimer's view an illustration of a gestalt organization in reading.

Although Wertheimer did not elaborate any further on this organization, and his observations remained quite general, he clearly alluded to the difficulty that would confront a theory of perceptual processes in reading stated in terms of (mechanical) unit identification and conversion. On the one hand, typical silent reading (in orthographic writing systems) can neither be characterized as literal (not all letters are identified) nor as purely holistic (letters still matter for reading, and not all words are overtly recognized). On the other hand, many letters and words are typically left unidentified in the course of proficient reading ${ }^{18}$. It is thus patent that the metaphors of unit (whether letters or whole words) identification and conversion, which fed the century-long debate between the proponents of letter-byletter or direct whole word recognition in reading, are unenlightening ${ }^{19}$. For the contents of the perceptual experience that underlies reading are not 'out there' on a sheet of paper waiting to be detected and internalized (in the form of mental representation). Since, on the one hand, the contents of experience in reading are not 'out there' waiting identification, internalization or conversion, and, on the other hand, a text represents a highly elaborated yet very compact material for experience, reading may serve as a living small-scale model of immediate experience illustrating the various issues relevant to microgenesis reviewed earlier in this essay. 
An interesting source of insights into reading comes from so-called 'deep dyslexia', a reading pathology due to brain damage where patients are characteristically unable to identify letters and read aloud pronounceable nonwords. They preserve nevertheless the ability to read words, though to a variable degree: nouns, verbs and adjectives are read best whereas conjunctions and articles are seldom read aloud. In reading content words, they quite often make semantic paralexias (e.g. reading 'priest' for 'church') and sometimes, but rather infrequently, visual (e.g. 'deep' for 'deer') or derivational (e.g. 'registered' for 'register') errors (Coltheart, Patterson, \& Marshall, 1980). One thing that is striking about observations on deep dyslexia is that they illustrate a condition in which perceptual-morphological, syntactic and semantic aspects of reading are all interwoven. Note, for instance, that in order to read 'priest' for 'church', words that visually have almost nothing in common, some perceptual-morphological processing of the printed word 'church' is necessary. This processing must, however, be insufficient for the overt identification of the target word, yet it must be sufficient to hit upon the sphere of meaning relevant to 'church' so as to allow the patient to respond using the word 'priest'. How could this occur where meaning and form alien to one another? On the other hand, it should also be borne in mind that, were the target a function word, chances are that a deep dyslexic patient would not be able to read it out loud. But how can he know that the target is a function word in so far as he is unable to overtly identify it? Clearly, in this example, form, meaning and function cannot be independent and mobilize processes that are intrinsically alien to one another.

The above example is also remarkably reminiscent of observations described by Werner (1956) and Conrad (1954) in which pathological behavior due to brain damage was presented as an arrest of the microgenetic process at an early stage of development, thereby letting occur unfinished 'products' in patients' behavior, that would normally undergo further development. Moreover, an examination of patients' semantic 'errors' produced for the same target word, whether in the same reading session or in different sessions, shows the same character of instability, sphere-like deployments and shifts of 'center of gravity' as those described by Werner with respect to Aktualgenese experiments conducted with normal subjects.

In a series of experiments undertaken recently in my laboratory we sought to further evaluate the postulates of immediate categorization and meaningfulness, selectivity, and global-to-local structure of microgenetic development in reading. These experiments were mainly intended to probe the structure of visual processes in reading but since reading normally applies to meaningful texts, other issues related to text interpretation, gradual development of meaning, and meaning and form relationship arose as well. In particular, we sought to evaluate the general hypothesis of a global-to-local structure of visual processes in reading by picking a specific instantiation of this hypothesis in terms of the selective processing of component letters depending on their orthographically discriminative character. The basic idea underlying this was the following: the selective processing of component letters that depends on their orthographically discriminative character presupposes prior identification of letter slots which are ambiguous and thus need discrimination. However, in order to determine which letter slots are ambiguous, it is first necessary to gather at least some 'knowledge' about the class of word shapes 
to which the target word belongs. Only a global word-shape-based process can bring about such 'knowledge'. Moreover, the very existence of letter processing after a prior word-shape preview implies that the latter global process is too coarsegrained or otherwise insufficient for word identification ${ }^{20}$. In this sense, the idea of the selective processing of component letters depending on their orthographic discriminativity lets us evaluate the underlying hypothesis of the global-to-local structure of perceptual differentiation in reading.

A few words of clarification may be needed here. What defines the ambiguous or critical letter slots in a word is the existence of its orthographic shapemates, i.e. other words sharing the same global shape (global word-form irrespective of internal letter features) but which differ locally with respect to component letters that occupy these slots. Of course, the letters in question are of similar stature (ascender to ascender, descender to descender, etc...); otherwise the words would not share the same global shape or be similar in regard to global word-forms. Because the primary global process is assumed to be coarse-grained, orthographic similarity is defined by the similarity of global word-forms at the level of spatial resolution which is insensitive to internal letter features. It is only in a later phase, and if the reader seeks local discrimination, that the visual system becomes sensitive to fine-level internal features. Thus, for instance, the fifth letter slot $(r)$ in the French word 'effarer' is ambiguous due to the existence of another word 'effacer' which shares with the former the same global shape (it is its shapemate) and the two words therefore can only be distinguished from one another by checking locally the fifth letter slot ( $r$ vs. $c)$. On the other hand, there is no ambiguous letter slot in the French word 'migraine' because no other French word shares its global shape. It can then be said that the fifth letter ' $r$ ' in 'effarer' is discriminative and hence critical for the identification of this word, whereas the ' $r$ ' in 'migraine' is noncritical because 'migraine' has no shapemates from which it would have to be distinguished.

The experiments which were conducted in order to evaluate the hypothesis of the selective processing of component letters were based on the letter cancellation technique or on the analyses of eye movements.

The letter cancellation technique (Corcoran, 1966; Healy, 1994) requires subjects to cross or circle each instance of a specific letter while reading a text for comprehension. It has been used to study the issue of perceptual units in reading (Drewnowski \& Healy, 1977; Hadley \& Healy, 1991; Healy, 1976) in relation to the effect of linguistic function (e.g. content vs. function words) on letter detectability (Greenberg \& Koriat, 1991; Koriat \& Greenberg, 1991; Koriat \& Greenberg, 1994), and in relation to the phonological status (e.g. pronounced vs. silent) of component letters (Corcoran, 1966). Studies based on this technique have shown that subjects always miss a certain amount of target letters while reading real text and that the rate of omission depends on certain parameters. For instance, letters in function words are more often missed than letters in content words (Greenberg \& Koriat, 1991), silent letters remain undetected more often than pronounced letters (Corcoran, 1966) and word meaning may also influence letter detection (Moravcsik \& Healy, 1995). Since the misdetections of target letters reported in these studies are quite systematic and take place in spite of efforts to detect all instances of these 
letters, it is assumed that they are indicative of the characteristics of the reading process.

In all experiments based on letter cancellation, the critical comparison was obtained by contrasting words in which the substitution of the target letter (most often ' $s$ ' and ' $r$ ') creates at least one orthographic shapemate, and words where no substitution of the target letter makes an existing word. The main prediction of these experiments was that because discriminative letter slots are likely to be targeted for local verification and thereby come to the center of local attention, the detection rate of target letters, which are critical to shapemate word differentiation, should be substantially higher than that of non-critical target letters, or, alternatively, that subjects should miss many more non-critical targets than critical ones. The main result of these experiments was that component letters that differentiate orthographic shapemates are better detected than letters that are in unambiguous slots (which give rise to twice as many detection errors). This critical-letter effect was obtained on five different passages of prose, as well as on meaningless scrambled assemblies of words. Moreover, it was found to criterially depend on orthographic similarity: the effect did not occur when orthographically legal letter substitutions altered word shape (e.g. 'mérite' vs. 'médite'). These findings unequivocally corroborate the general idea that local letter-level analyses are pretuned by an earlier global process and thus they lend support to the hypothesis of the global-to-local structure of perceptual differentiation in reading ${ }^{21}$.

Experiments based on the analyses of the eye fixations of subjects reading various types of text provided independent evidence of the above critical-letter effect and brought additional insights into the structure of visual and interpretive processes in reading that are relevant here. First, the results substantiated the hypothesis of the orthographic determinants of fixation locations in words by showing a systematic relationship between the distribution of fixation locations and the presence or absence of orthographically discriminative letters: eye fixations tended to land on the area of discriminative letters in words that have orthographic shapemates and to spread over the body of words with unambiguous shapes. Second, these results showed that the presence or absence of orthographically discriminative information does not affect the probability of fixating a (content) word: readers fixated just as much words that have orthographic shapemates and words that have unambiguous shapes. Third, the results showed that while reading normal two-page texts, subjects centrally fixated only $44 \%$ of the words.

The finding that an orthographically ambiguous word (i.e. word having shapemates) will not necessarily be fixated shows that the 'decision' of whether to fixate a word is not governed merely by orthographic considerations (e.g. the search to explicitly identify words) but by the ongoing process of text comprehension (see also Balota, Pollatsek, \& Rayner, 1985; Ehrlich \& Rayner, 1981; Rayner \& Well, 1996). This conclusion, along with the consideration that less than $50 \%$ of words were centrally fixated in our experiments, suggests that parafoveally-gained information may be sufficiently meaningful for it to take part in text interpretation. This is consistent with the proposition that meaning goes hand-in-hand with perceptual categorization, developing along the same lines from general to specific, from relatively vague and global to articulate, precise, and local. 
The finding that readers fixate not only words that have ambiguous shapes but also words that are unambiguous - whether because they have orthographically unique shapes and/or due to strong contextual evidence - suggests that definite word identification does not take place in parafoveal vision. We may thus ask the following question: if only words gaining foveal fixation are explicitly identified, how is it that subjects can skip more than $50 \%$ of words and still properly understand a text, as is shown by their ability to correctly answer questions about the content of what they have read? It is noteworthy that in our experiments this skipping very often concerned content words - one out of three 7-10 letter words (mainly content words) were not fixated by our subjects - and cannot therefore be attributed to a word class effect (e.g. certain function words being selectively skipped because they are highly predictable on syntactic grounds). Clearly, these results indicate that text comprehension in reading does not require explicit identification of all component words. This is not to suggest that the meaning of words that are not explicitly identified is simply ignored. Although parafoveal inspection does not allow for explicit word identification it does appear to feed the ongoing text comprehension process with adequate information (see also Lavigne, Vitu, \& d'Ydewalle, 2000). This information may only be partial or incomplete from the point of view of a dictionary definition of word meaning, but it nevertheless appears to be contextually appropriate and sufficient for the comprehension of a given text $\mathrm{t}^{22}$. In any case, if parafoveal inspection can both constrain word discrimination and inform the process of text comprehension, there are grounds in psychology for the concept of immediate coarse-grained categorization of (printed) forms that is directly meaning-laden (due in part to a form/meaning relationship). This is precisely what microgenetic theory stipulates.

The foregoing example is admittedly no more than a partial illustration of the application of microgenetic thinking to the research context of reading. Beyond its relevance for a theory of visual processes in reading, the primary purpose of this illustration was to show that the microgenetic theory offers a viable and productive research strategy. The subversive quality of the theory, which even on partial and fairly local application forces a deep revision of the field of reading research, shows that microgenesis is not a mere collection of local hypotheses, that it makes a coherent though as yet emergent framework for the study of lived experience. After all, the issue at stake is genetic phenomenological science of embodied cognition.

Prof. Victor Rosenthal

Centre Paul Broca

2ter rue d'Alésia

75014 Paris, France. 
${ }^{1}$ It should be underscored that microgenesis shared with the Berlin School of Gestalt theory some of its basic tenets (e.g. the concept of field, the idea of stabilization in a dynamic system) and its phenomenological orientation. However, it proceeded in directions neglected by the gestaltists: it focused on fine-grained temporal dynamics of psychological processes and on the categorial character of meaning and perception; postulated that perceptual experience is directly meaning-laden and intrinsically emotional, that forms are inherently semantic, and not merely morphological constructs. In contrast to the Berlin group, early work on microgenesis was highly concerned with language and language development, and with cognitive disorders due to brain damage.

2 Action should be distinguished from mechanical reaction. What characterizes genuine action is that it implies the autonomy and spontaneity of an agent, and a knowledge of the environment in which the action will take place. Indeed, the very possibility of autonomous and spontaneous action is ipso facto a demonstration of the agent's of knowledge of the environment. To put it in terms of a phenomenology of action (and indeed also of living): doing is a basic form of knowing (see Arendt, 1958; Whitehead, 1983).

${ }^{3}$ The popular flowchart models (see e.g. Shallice, 1987; Shallice, 1988) where in order to acquire meaning, a semantically vacuous categorical percept has to access so called 'semantic memory', and where various 'semantic effects' are dealt with by invoking the concept of 'level of activation', do not provide a better solution to this problem. For, if semantics postdates morphology in the course of perception, and the latter is independent of the former, no room is left for the influence of meaning and value upon the size of perceived objects.

${ }^{4}$ In line with Gestalt tradition, the microgenetic theory assumes that perception generically instantiates the structure of cognition.

${ }^{5}$ Correlatively, it thus becomes understandable why cognitive and perceptual processes are not infallible. Although microgenesis is globally adequate for our conditions of living, its anticipatory and directly categorial character conditions its potential failures. Accordingly, the observation that cognitive, perceptual or language processes are intrinsically fallible becomes a source of insights into the structure of cognition (see Rosenthal \& Bisiacchi, 1997). For instance, the obstinate resistance of 'perceptual errors' to contradictory evidence handily illustrates the 'cost' of the anticipatory and directly categorial character of microgenetic differentiation.

${ }^{6}$ Genetic refers here to the developmental dynamics of a process, not to a genome or to an adjectival use of the metaphor 'genetic program'.

${ }^{7}$ It goes without saying that it is not the real line that can formally represent autochronic time. Self-generation of time can only occur by fits and starts (or by pulsing) with variable periodicity.

${ }^{8}$ We are concerned here with the tentative explanation of the dynamics of processes in themselves. The reader should, however, be aware that the general proposal bears on the dual structure of autochronic time.

${ }^{9}$ We may sometimes have an elusive, fading impression of intermediate deployments which nevertheless escapes thematization however much we strive to bring it to conscious inspection.

${ }^{10}$ For instance, Werner noted that colors are experienced not only in terms of hue, brightness, and saturation but also in terms of being strong or weak, cool or warm; lines not only have extent and curvature, etc., but may be seen as gay or sad...

${ }^{11}$ Note that physiognomic perception further instantiates the value-laden character of perceptual experience which I discussed in the initial sections of this essay. The perceptual world is indeed directly invested with values by virtue of the same dynamic principles that confer 'interiority' on perceived objects and dynamic configurations and urge perceivers on to action. Accordingly, values are not indirectly associated with objects on the basis of past experience and/or rational evaluation (though of course in certain particular situations an object may be valued on the basis of rational evaluation) any more than expressive qualities are inferred by analogy.

12 (Shanon, 1982).

${ }^{13}$ This idea is even presented unquestioned in recent handbooks (see e.g. Palmer, 1999). The logical difficulties with which this 'mosaic theory' is confronted are hardly mentioned.

${ }^{14}$ The magnocellular system appears to exert control on eye movement.

${ }^{15}$ Although the $\mathrm{M}$ cells are often described as detectors of movement, it should be borne in mind that spatial and temporal discontinuities induced by movement are the very condition for form perception. Indeed, selfinduced (eye and/or head) movements are necessary for seeing, and the 'static retina', i.e. when eye movements are prevented or artificially compensated for, is blind (see Yarbus, 1967). Incidentally, this latter observation was anticipated by Husserl and Merleau-Ponty.

${ }^{16}$ The global character is obvious since the figure cannot be constructed from its components. The dynamics can be explained by the co-presence (or co-occurrence in time) of inducers (fragments) and their joint displacement upon self-induced movement (e.g. eye-movement).

${ }^{17}$ Note also that although subjective figures are often illustrated by geometrical forms, geometric regularity is unnecessary, and any sensible figure, even irregular, can arise under similar conditions. The phenomenal completion is thus not an effect of Euclidean principles encoded in the brain. 


\footnotetext{
${ }^{18}$ Rosenthal, Parisse, and Chainay (2002) showed that subjects skip (i.e. do not fixate in central vision) more than $50 \%$ of words while reading regular texts.

${ }^{19}$ It bears noting that the so-called interactive solution (viz. interactive recognition of letters and whole words, see e.g. McClelland \& Rumelhart, 1981; Rumelhart \& McClelland, 1982) is in this respect no solution at all as it presupposes an a priori segmentation into relevant units.

${ }^{20}$ The foregoing formulation should not be interpreted literally as suggesting a two-stage (first global, then local) theory of visual processes in reading, which, let it be said in passing, would be at odds with the microgenetic theory of gradual development. It simply intends to instantiate the idea of the temporal precedence of global coarse-grained over local selective and fine-grained differentiation.

${ }^{21}$ One may notice, on the other hand, that the necessity of differentiating words having the same global shape presupposes the prior occurrence of a process that categorizes words on the basis of their global shape. In this sense, these results corroborate the proposition that perceptual differentiation involves immediate categorization.

${ }^{22}$ Since overt identification of all words is not necessary for contextually appropriate text comprehension, the proportion of words being explicitly identified may vary depending on strategic attentional factors, the type of text being read, and the individual's interests and reading skills (see also the concept of the effective visual field in Marcel, 1974, and the discussion of the use of context).
}

\section{REFERENCES}

ARENDT, H. (1958). The Human Condition. Chicago: University of Chicago Press.

ARnheim, R. (1954). Art and visual perception; a psychology of the creative eye. Berkeley: University of California Press.

ARnheIM, R. (1969). Visual thinking. Berkeley: University of California Press.

Balota, D. A., Pollatsek, A., \& Rayner, K. (1985). The interaction of contextual constraints and parafoveal visual information in reading. Cognitive Psychology, 17(3), 364-90.

BozzI, P. (1989). Fenomenologia Sperimentale. Bologna, Italy: Il Mulino.

BRAND, J. (1971). Classification without identification in visual search. Quarterly Journal of Experimental Psychology, 23, 178-186.

BRUNER, J. S., \& Goodman, C. C. (1947). Value and need as organizing factors in perception. Journal of Abnormal Social Psychology, 42, 33-44.

Cadiot, P., \& Visetti, Y. M. (2001). Pour une théorie des formes sémantiques. Paris: Presses Universitaires de France.

CATÁN, L. (1986). The dynamic display of process: Historical development and contemporary uses of the microgenetic method. Human Development, 29, 252-263.

Coltheart, M., Patterson, K., \& Marshall, J. C. (Eds.). (1980). Deep dyslexia. London: Routledge \& Kegan Paul.

CONRAD, K. (1954). New problems of aphasia. Brain, 77(4), 491-509.

CorCoran, D. W. J. (1966). An acoustic factor in letter cancellation. Nature, 210, 658.

DAvis, G., \& Driver, J. (1994). Parallel detection of Kanizsa subjective figures in human visual system. Nature, 371, 791-793.

Drewnowski, A., \& HeAly, A. F. (1977). Detection errors on the and and: Evidence for reading units larger then the word. Memory \& Cognition, 5, 636-647.

EHRLich, S. F., \& RAYNER, K. (1981). Contextual effects on word perception and eye movements during reading. Journal of Verbal Learning and Verbal Behavior, 20, 641-655.

FODOR, J. A. (1964). Review of Symbol Formation by Heinz Werner and Bernard Kaplan. Language, 40, 566-579.

Gibson, J. J. (1979). The Ecological Approach to Visual Perception. Hillsdale, N.J.: Lawrence Erlbaum.

GreenberG, S. N., \& Koriat, A. (1991). The missing-letter effect for common function words depends on their linguistic function in the phrase. Journal of Experimental Psychology: Learning, Memory, and Cognition, 17(6), 1051-1061.

GuRwitsch, A. (1957). Théorie du champ de la conscience. Paris: Desclée de Brouver.

Gurwitsch, A. (1966). Studies in Phenomenology and Psychology. Evanston: Northwestern University Press.

Hadley, J. A., \& Healy, A. F. (1991). When are reading units larger than the letter? Refinement of the unitization reading model. Journal of Experimental Psychology: Learning, Memory, and Cognition, 17(6), 1062-1073.

HEALY, A. F. (1976). Detection errors on the word the: evidence for reading units larger than letters. Journal of Experimental Psychology: Human Perception and Performance, 2(2), 235-242. 
HeAly, A. F. (1994). Letter detection: a window to unitization and other cognitive processes in reading text. Psychonomic Bulletin \& Review, 1(3), 333-344.

INGLING, N. (1972). Categorization: a mechanism for rapid information processing. Journal of Experimental Psychology, 94, 239-243.

KanizSA, G. (1976). Subjective contours. Scientific American, 234(4), 48-52.

Kanizsa, G. (1979). Organization in Vision: Essays on Gestalt Perception. New York: Praeger Press.

KÖHLER, W. (1938). The Place of Value in a World of Facts. New York: Liveright.

KöHLER, W. (1947). Gestalt Psychology. (Revised Edition ed.). New York: Liveright.

Koriat, A., \& GreEnBERG, S. N. (1991). Syntactic control of letter detection: Evidence from English and Hebrew non-words. Journal of Experimental Psychology: Learning, Memory, and Cognition, 17(6), 1035-1050.

Koriat, A., \& GREENBERG, S. N. (1994). The extraction of phrase structure during reading: evidence from letter detection errors. Psychonomic Bulletin \& Review, 1(3), 345-356.

LAMbie, J. A., \& MARCEL, A. J. (2002). Consciousness and the varieties of emotion experience: a theoretical framework. Psychological Review, 109(2), 219-259.

LAMME, V. A. (1995). The neurophysiology of figure-ground segregation in primary visual cortex. Journal of Neuroscience, 15, 1605-1615.

Lavigne, F., Vitu, F., \& d'Ydewalle, G. (2000). The influence of semantic context on initial eye landing sites in words. Acta Psychologica, 104, 191-214.

LehmKuhle, S. (1993). Neurological basis of visual processes in reading. In D. M. Willows, R. S. Kruk, \& E. Corcos (Eds.), Visual processes in reading and reading disabilities (pp. 77-94). Hillsdale, N.J.: Lawrence Erlbaum Associates.

LeSHER, G. W. (1995). Illusory contours: Toward a neurally based perceptual theory. Psychonomic Bulletin and Review, 2, 279-321.

Leventhal, A. G., Rodieck, R. W., \& Dreher, B. (1981). Retinal ganglion cell classes in the Old World monkey: morphology and central projections. Science, 213(4512), 1139-42.

LhermitTe, F. (1983). 'Utilization behaviour' and its relation to lesions of the frontal lobes. Brain, 106(Pt 2), 237-55.

Livingstone, M., \& Hubel, D. (1988). Segregation of form, color, movement, and depth: anatomy, physiology, and perception. Science, 240(4853), 740-9.

MARCEL, A. J. (1974). The effective visual field and the use of context in fast and slow readers of two ages. British Journal of Psychology, 65(4), 479-492.

MARCEL, A. J. (1993). Slippage in the unity of consciousness. Ciba Foundation Symposium, 174, 168-80.

Mattingley, J. B., Davis, G., \& Driver, J. (1997). Preattentive filling-in of visual surfaces in parietal extinction. Science, 275, 671-674.

McClelland, J. L., \& Rumelhart, D. E. (1981). An interactive activation model of context effects in letter perception: Part 1 An account of basic findings. Psychological Review, 88, 375-407.

MERIGAN, W. H., \& MAUnSELl, H. R. (1993). How parallel are the primate visual pathways? Annual Review of Neuroscience, 16, 369-402.

Moravcsik, J. E., \& Healy, A. F. (1995). Effect of meaning on letter detection. Journal of Experimental Psychology: Learning, Memory, and Cognition, 21(1), 82-95.

O'Regan, J. K. (1992). Solving the "real" mysteries of visual perception: the world as an outside memory. Canadian Journal of Psychology, 46(3), 461-88.

O'Regan, J. K., \& NoË, A. (2002). A sensory-motor account of vision and visual consciousness. Behavoral and Brain Sciences, 24(5).

Palmer, S. E. (1999). Vision Science: Photons to Phenomenology. Cambridge, MA.: The MIT Press.

PessoA, L., Thompson, E., \& Nö̈, A. (1998). Finding out about filling-in: A guide to perceptual completion for visual science and the philosophy of perception. Behavioral and Brain Sciences, 21, 723-802.

RASTIER, F. (1997). Meaning and textuality. Toronto: University of Toronto Press.

RAYNER, K., \& WeLL, A. D. (1996). Effects of contextual constraint on eye movements in reading: A further examination. Psychonomic Bulletin and Review, 3, 504-509.

Rosenthal, V. (1993). Cognition, vie et... temps. Intellectica, 16, 175-207.

Rosenthal, V., \& Bisiacchi, P. (1997). Tacit integration and referential structure in the language comprehension of aphasics and normals. Journal of Psycholinguistic Research, 26(5), 557-580.

Rosenthal, V., Parisse, C., \& Chainay, H. (2002). A critical-letter effect in reading. (submitted).

Rosenthal, V., \& Visetti, Y. M. (1999). Sens et temps de la Gestalt. Intellectica, 28, 147-227.

Rumelhart, D. E., \& McClelland, J. L. (1982). An interactive activation model of context effects in letter perception: Part 2. The contextual enhancement effect and some tests and extensions of the model. Psychological Review, 89(1), 60-94.

SANDER, F. (1930). Structures, totality of experience, and gestalt. In C. Murchinson (Ed.), Psychologies of 1930 (pp. 188-204.). Worcester, MA.: Clark University Press. 
Semenza, C., Bisiacchi, P., \& Rosenthal, V. (1988). A function for cognitive neuropsychology. In G. Denes, P. Bisiacchi, \& C. Semenza (Eds.), Perspectives on cognitive neuropsychology (pp. 3-30). London: Lawrence Erlbaum Associates.

ShalliCe, T. (1987). Impairments of semantic processing: multiple dissociations. In M. Coltheart, R. Job, \& G. Sartori (Eds.), The cognitive neuropsychology of language (pp. 111-129). London: Lawrence Erlbaum Associates.

Shallice, T. (1988). From neuropsychology to mental structure. Cambridge: Cambridge University Press.

Shallice, T., Burgess, P. W., Schon, F., \& BaXter, D. M. (1989). The origins of utilization behaviour. Brain, 112(Pt 6), 1587-98.

Shanon, B. (1982). The Myth of the Box and the Package. Jerusalem: The Rotman Center for Cognitive Science: The Hebrew University.

Shapley, M., \& Perry, V. H. (1986). Cat and monkey retinal ganglion cells and their visual functional roles. Trends in Neuroscience, 9, 229-235.

UNDERWOOD, G. (Ed.). (1998). Eye guidance in reading and scene perception. Oxford: Elsevier Science Ltd.

VicARIO, G. B. (1993). On Experimental Phenomenology. In S. C. Masin (Ed.), Foundations of Perceptual Theory. Amsterdam, The Netherlands: Elsevier Science.

Vygotsky, L. S. (1978). Mind in Society: The Development of Higher Psychological Processes. Cambridge, MA.: Harvard University Press.

Werner, H. (1930). Die Rolle der Sprachempfindung im Prozess der Gestaltung ausdrucksmässig erlebter Wörter. Zeitschrift für Psychologie, 117, 230-254.

Werner, H. (1956). Microgenesis and aphasia. Journal of Abnormal Social Psychology, 52, 347-353.

Werner, H. (1957). Comparative psychology of mental development. (Rev. ed.). New York: International Universities Press.

Werner, H., \& Kaplan, B. (1956). The developmental approach to cognition: its relevance to the psychological interpretation of antropological and ethnolinguistic data. American Anthropologist, 58, 866-880.

WERNER, H., \& KAPLAN, B. (1963). Symbol formation: an organismic-developmental approach to language and the expression of thought. New York: Wiley.

Werner, H., \& WAPNER, S. (1952). Toward a general theory of perception. Psychological Review, 59, 324338.

Whitehead, A. N. (1983). Concept of Nature. Cambridge: Cambridge University Press.

YARBus, A. L. (1967). Eye movements and vision (L. A. Riggs, Trans.). New York: Plenum Press. 